\title{
Educação infantil e mundo político
}

\author{
Deise Gonçalves Nunes
}

Universidade Federal Fluminense (UFF)

\section{Educação infantil e mundo político}

Resumo: Neste estudo ${ }^{1}$, analisa-se a forma como a organização de saberes e práticas no campo da Educação Infantil reflete e condiciona a internalização da ideia de mundo político, tanto na dimensão do conformismo e da reiteração da ordem quanto da resistência e construção de uma nova sociedade. Na primeira parte focaliza-se a educação infantil como produto histórico, demonstrando como as práticas inscritas no seu interior veem sendo tecidas a partir de uma determinada concepção de assistência social dominante no campo das políticas sociais. Na segunda, aborda-se o educador infantil como um ser social que tem parte de sua subjetividade formada a partir das determinações materiais de sua prática profissional. Por fim, apresenta-se, a título de conclusão, uma breve reflexão sobre a educação infantil como um acontecimento político que é socialmente determinado e que nos fala de relações e poderes que podem definir sociabilidades mais ou menos afeitas à ordem social dominante.

Palavras-chave: educação infantil, subjetividades, mundo político.

\section{Early Childhood Education and the Political World}

Abstract: This study analyzes how the organization of knowledge and practices in the field of Early Childhood Education conditions the idea of the political world. It can function both to encourage conformism and the reiteration of order as well as to build resistance and encourage the construction of a new society. The first portion of the study focuses on early childhood as a historic product, demonstrating how the practices inscribed within it have been woven from a given concept of dominant social assistance in the field of social policies. It then approaches the elementary school teacher as a social being who has part of his or her subjectivity formed from the material determinations of his or her professional practice. Finally, it concludes with a brief review of early childhood education as a political event that is socially determined and which involves relations and powers that can define sociabilities that are more or less inured to the dominant social order.

Key words: childhood education, subjectivities, political world. 


\section{Introdução}

A relação entre a educação infantil pública e o mundo político fundamenta-se nas determinações sócio-históricas que ocorrem dentro de um emergente padrão de proteção social - o surgimento de creches e pré-escolas - destinado às classes trabalhadoras, sob determinada forma de apreensão ideológica e cultural, especialmente dirigida às mulheres trabalhadoras e a seus filhos pequenos. A história da educação infantil voltada para os filhos dos trabalhadores tem sido desenvolvida através de práticas redutoras e/ou rotuladoras das diferenças sociais que se materializaram, ao longo dos anos, em ambientes funcionais à reiteração de relações sociais paternalistas e autoritárias.

Os espaços físicos inadequados, a falta de recursos e materiais pedagógicos, o pessoal mal remunerado e a parceria entre o público e o privado sem fins lucrativos formaram a rede de atendimento que, durante muitos anos, dominou a educação voltada para as crianças pequenas e pobres na faixa de zero a seis anos. Esta rede foi iniciada ainda nos anos 1930, sob a égide das creches empresariais e/ou assistenciais e filantrópicas, e ampliou-se entre os anos 1950 e 70, sob a influência da Legião Brasileira de Assistência (LBA) numa perspectiva de ampliação da rede em parceria com entidades comunitárias.

Concebemos que o ato de educar - que no caso da educação infantil combina os cuidados físicos e a construção de conhecimentos - envolve a produção de subjetividades que, segundo Guattari e Rolnik (2005), formam a mais importante matéria-prima do mundo capitalista. As condições de trabalho do educador infantil e a relação que ele estabelece com a criança pequena, por si só, já constituem importante ferramenta para se avaliar como o ato de educar pode ser mais ou menos inovador, democrático e crítico. No frágil contexto imediato e cotidiano da educação infantil pública e gratuita, podemos avaliar que o encontro entre educador e criança pode ser uma possibilidade de diálogo, organizado a partir de singularidades e diferenças, ou uma possibilidade total de apagamento da criança, remetendo-a às diferenças sociais que são estruturadas e estruturáveis pelas desigualdades sociais ${ }^{2}$.

No caso da educação infantil popular, ocorre uma dupla determinação que pode interferir na constru- ção das relações entre a educação e a política. Em primeiro lugar, ela se origina num terreno concebido a partir de relações autoritárias, clientelistas e de tutela, que têm suas origens nos antigos educandários, semi-internatos ou creches para os filhos das mulheres trabalhadoras, que podiam transformar o outro a criança e sua família - num pedinte, num subalterno, sem voz nem reconhecimento social. Em segundo lugar, ela se funda numa dada concepção de infância como um tempo que é, ao mesmo tempo, familiar e estranho, para o qual é dirigido um olhar que mistura os sentimentos de proximidade com a própria infância de cada sujeito, um olhar de estranheza para com aquilo que a criança concreta do cotidiano e que não pertence ao mundo adulto. Esta estranheza pode se manifestar em atitudes que misturam o disciplinamento, o emudecimento das crianças frente às expectativas dos adultos, nos seus sentimentos, nas suas emoções e desejos. Estas determinações demonstram que a educação infantil, como produto histórico, não está dissociada do exercício de controle social sobre as múltiplas expressões da questão social, e revelam como este controle se estabelece no cotidiano das práticas e da formação de saberes.

\section{A educação infantil brasileira como um produto histórico}

A institucionalidade da educação infantil no Brasil ocorre na década de 1930, quando importantes acontecimentos sociopolíticos - atravessados por relações sociais contraditórias e ambíguas - marcaram a história do desenvolvimento capitalista entre nós. Foi neste
A institucionalidade da educação infantil no Brasil ocorre na década de 1930 , quando importantes acontecimentos sociopolíticos atravessados por relações sociais contraditórias e

$$
\text { ambíguas - marcaram a }
$$

história do desenvolvimento capitalista entre nós. ambiente que mulheres trabalhadoras e seus filhos pequenos entraram na cena pública como protagonistas e demandatários de um tipo especial de política social: aquela desenvolvida nas creches, berçários e abrigos. Entretanto, essas necessidades, ao se transformarem em demandas socialmente determinadas e articuladas à questão social, sofreram um processo de ocultamento de suas raízes sociais e econômicas e passaram a ser concebidas como necessidades individuais, de sujeitos - em especial as mulheres no exercício de sua maternidade - que logo passaram a ser concebidas como mal-adaptadas, disfuncionais. O viés ideológico e moralizante ocultou as raízes sociopolíticas das necessidades sociais e, 
no caso particular das creches e pré-escolas, fixou o lugar social da mãe operária como o lugar desenraizado da moral e responsável pela formação de crianças propensas a serem problemáticas. As creches seriam, então, um "mal necessário"3 um lugar de formação compensatória dos deslizes higienistas e moralistas da então nascente classe operária.

As mães operárias e seus filhos pequenos se tornaram, nesse contexto, protagonistas desiguais, inseridos em relações de classe que logo os transformaram em subalternos, pedintes, destituídos de direitos e com tendências a comportamentos desviantes. Entretanto, no contexto contraditório das relações sociais e na perspectiva histórica da transformação social, esses sujeitos encontram, dentro destas práticas, espaços de luta e ruptura. No Brasil, o processo de ruptura com esta perspectiva ídeopolítica de atendimento começou a tomar corpo na década de 1970 com a organização de movimentos sociais que lutaram pela ampliação de creches, consolidando-se nos anos 1990, com o reconhecimento da educação infantil como um direito de toda e qualquer criança ${ }^{4}$.

Os saberes e as práticas instituídas ao longo deste processo histórico revelam diferentes formas de legitimidade e de institucionalidade que envolvem diferentes abordagens sobre a infância e sobre o desenvolvimento social e cognitivo das crianças mais pobres. No que diz respeito à abordagem teórica sobre a infância, as teorias psicológicas, sobretudo as da psicologia do desenvolvimento, reproduziram a concepção prevalente de conhecimento que segmenta os diferentes níveis da vida em sociedade. Rabello (1998) mostra como a psicologia do desenvolvimento cristaliza essa ideia, através de diferentes correntes teóricas. Na área da sociologia e antropologia, essa segmentação aparece nas concepções dominantes sobre os processos de socialização entendidos como interiorização de hábitos culturais e valores sociais dominantes em uma dada formação social. A cultura, como expressão do consenso, seria integrada à personalidade da criança, e aquela mais "socializada" seria a mais adaptada à cultura dominante. Essa concepção, reiterativa de uma dada visão de sociabilidade, faz com que as normas e regras da vida em comum se apresentem, desde a primeira infância, como produto de uma vontade geral, de uma norma coletiva que deve conduzir e controlar o comportamento de todos.

Esses conjuntos de interpretações, hegemônicos até meados dos anos 80 do século passado, tanto na área da psicologia quanto na área da sociologia, materializaram-se em práticas sociais de caráter intervencionista, tutelar e assistencialista que se manifestam em muitas instituições de educação infantil até os dias atuais. Tais práticas se constituem com base numa ideia universal de desenvolvimento hu- mano e de fusão entre o indivíduo e a sociedade, regida por uma plena adaptação às regras da vida social, através da qual a criança terá reconhecida a sua identidade social, cultural e cognitiva.

Diversas abordagens indicam que deve haver maior investimento social na área da infância, pois é lá que o indivíduo apreende os padrões de comportamento e de socialização. "É de pequeno que se torce o pepino", parece ser mais do que um ditado popular, um eixo de condução pedagógica de significativa repercussão nas práticas sociais voltadas para os segmentos mais pobres da população. A submissão da criança, no interior das creches e pré-escolas a rígidos padrões de controle de comportamento - incluindo-se, aqui, os padrões higienistas - se legitimariam, no plano ídeo-político, dentro de uma concepção de creche como doação, benesse social a que crianças e mães deveriam ser gratas e absolutamente subalternizadas. Ao se cristalizarem em práticas, essas ações criam, nos indivíduos que delas dependem, a ideia de que são, de fato, inferiores e diferentes. Aqui a creche se torna absolutamente funcional à perspectiva de assistência social que tutela os mais pobres e os transforma em sub-cidadãos. Em termos históricos, podemos definir como a grande fase do assistencialismo aquela que vai dos anos 1930 até meados da década de 1970, quando o padrão de política social mais geral da sociedade brasileira começa a mudar. Nesta fase, houve a gradual montagem de um projeto multidisciplinar de intervenção na educação infantil que tinha os seguintes eixos condutores:

a) Um rígido controle sobre os hábitos familiares da criança;

b) Uma concepção meritocrática da vaga, condicionada ao trabalho da mulher fora do lar;

c) Um controle sobre a maternidade, especialmente sobre o período de amamentação;

d) Um disciplinamento sobre o modo de vida das famílias, em especial sobre os seus hábitos higiênicos e morais 5 .

A partir dos anos 1970, importantes mudanças ocorreram no cenário das relações sociais e políticas do país e elas determinaram significativas alterações nas políticas sociais, especialmente na assistência, saúde e educação. O processo de redemocratização do país e a reorganização do movimento operário e social serão os principais determinantes destas transformações. A área da infância talvez tenha protagonizado um dos giros mais significativos da história recente da política social, com o estabelecimento de um amplo debate nacional que indicava a urgente necessidade de se modificar o então vigente Código de Menores. A precarização do atendimento a crianças dependentes da ação do Estado, a dinâmica de criminalização e penalização sobre os mais pobres, direcionariam a grande mobilização nacional em prol de mudan- 
ças nas leis e nas práticas sociais. Tais mudanças tiveram o seu aparecimento e sua legitimidade nos anos 1990, com a promulgação do Estatuto da Criança e do Adolescente (ECA, Lei Federal n. 8.069, de 13 de julho de 1990) e com a Lei de Diretrizes e Bases da Educação Nacional (LDB, Lei n. 9.394, de 20 de dezembro de 1996). Uma e outra chamam a atenção para um novo e significativo avanço: a criança passaria a ser concebida como um sujeito de direitos. É neste cenário que a educação infantil ganhou uma nova roupagem e passou a integrar-se às políticas de educação através da sua integração aos sistemas municipais de ensino, organizados à luz da diretriz descentralizadora das políticas sociais, emanadas e emolduradas no contexto da reforma do Estado e do neoliberalismo.

Assim, iniciamos o século 21 com um momento inédito na história da educação infantil: a sua integração aos sistemas municipais de ensino. Entretanto, a passagem da educação infantil da área assistencial para a educacional ainda não produziu as esperadas melhorias em termos de qualidade de atendimento, de ampliação de vagas e democratização da gestão. Isso ocorre porque assistimos a uma "passagem" e não a uma política pública de integração que deveria estar fundada em princípios de transparência, publicização dos processos e resultados, delimitação de critérios de monitoramento e avaliação. Em geral, essa "passagem" está sendo marcada pela coexistência antagônica de dois sistemas: um constituído pelas pré-escolas que já eram das redes públicas de educação e outro formado pelas instituições que migraram da área assistencial e que entram nos sistemas municipais como entidades conveniadas.

Essa coexistência, ainda que conflituosa e banhada em muitas contradições, tem permitido a construção de um até então inédito sentido de educação infantil como integrante no campo da educação. Tal construção tem servido para fundamentar as ações renovadas dos trabalhadores da educação, dos movimentos sociais e dos sindicatos, revertendo ações de cunho paternalista/clientelista. Isso demonstra quanto a integração da educação infantil aos sistemas municipais de ensino transforma-se em uma arena, na qual estão em luta projetos societários de diferentes orientações que apontam para diferentes apropriações, imersas na cultura política local ${ }^{6}$.

A importância da noção politicamente construída sobre a criança cidadã, principalmente após a promulgação do Estatuto da Criança e do Adolescente, pode ser lida, desde o início dos anos 1990, no campo da educação infantil, como a luta pela educação infantil como um direito de cidadania, que deve ser implementado pelo Estado através da ampliação de vagas nas escolas públicas. Esse sentido vem sendo expresso na parcela mais organizada dos movimentos sociais de educação infantil, sobretudo dos fóruns populares, mobilizados para disputá-lo tanto no âmbito do seu reconhecimento quanto de sua regulação. Podemos afirmar que o campo político sobre o qual está sendo constituída essa integração em nada é consensual ou "integrativo" no sentido de normativo, ordenado ou consentido. Isto ocorre porque o processo de transferência das creches se dá numa conjuntura bastante paradoxal: a entrada nos sistemas municipais força o Estado a assumir a educação infantil em um contexto no qual, por força do neoliberalismo, a sociedade civil é chamada a assumir as responsabilidades sociais típicas do Estado. Nessa realidade, a incorporação da educação infantil é atravessada por muitas ambiguidades e contradições que repercutem não só no processo de trabalho dos educadores, mas também nas suas formas organizativas de luta. Assim, encontrarmos trabalhadores que, para além da clássica disjunção entre "leigos" e "formados", possuem diferentes vínculos empregatícios e diferentes identificações ideológicas: funcionários públicos concursados, funcionários contratados pelo Estado para prestação de serviços por tempo determinado, prestadores de serviços terceirizados etc.

Ao mesmo tempo, deve-se considerar que, apesar de os movimentos sociais, em especial o Fórum Permanente de Educação Infantil, terem uma relevante presença na politização dos debates sobre a educação infantil, não houve, ainda, a tradução da agenda desse importante movimento em ação política, que de fato redefina os rumos dessa passagem, ou que entre na negociação dos conflitos a ela inerentes. Sendo assim, as tradições populistas, clientelistas e autoritárias que atravessam os interesses da cultura política local se presentificam nessa fase de transição, despolitizando o debate sem um diálogo mais comprometido com os movimentos sociais.

\section{$O$ educador infantil: entre o voluntarismo e o profissionalismo}

O trabalho do educador infantil teve o seu aparecimento e a sua regulação social determinados por condições objetivas, dadas pela própria dinâmica societária e por condições subjetivas, formadas pela internalização de um determinado modo de conceber a educação infantil e o ato de educar, derivados das condições objetivas de trabalho.

Pela retomada histórica apresentada nos itens antecedentes, observa-se que tais condições objetivas materializaram relações sociais fortemente fincadas em uma rígida estrutura de poder e de uma cultura política com feições que circulavam entre a religiosidade, o comunitarismo ou o assistencialismo e, mais recentemente, com um perfil mais educacional. Tais feições, ainda que assentadas em determi- 
nadas representações de criança e sua família, eram apoiadas e estruturadas em trabalho sociopedagógico disciplinador e regulador que, apesar do fundo autoritário, revestia-se de um caráter de benevolência, ajuda e assistência.

Estas relações objetivas contraditórias e ambíguas emergiam de específicas condições de trabalho em que o exercício profissional tinha uma dimensão fortemente amparada no voluntarismo, pouco afeto à relação de compra e venda da força de trabalho do educador enquanto mercadoria inserida nas relações capitalistas de produção. Ou, quando esta relação existia, não necessariamente passava - e podemos afirmar que isto ocorre até os dias atuais - por uma regulação contratual de compra e venda de uma dada força de trabalho. Trabalho com a hipótese de que a confusão de papéis e de funções, entre o educador e o voluntário, foi reforçada por uma débil noção da finalidade social do trabalho desenvolvido. A obscuridade da experiência de trabalho como algo socialmente determinado, regulado e, portanto, com uma finalidade social, era condicionada pela ênfase nos cuidados higiênicos, desprovidos de qualquer saber. Esta indeterminação do saber e da finalidade social do exercício profissional tinha a propriedade de desarmar qualquer interrogação, qualquer movimento de luta em sentido contrário. Além disso, ela se refratava na confusão de signos utilizados para designar o profissional da educação infantil: pajens, monitores, recreadores, todos envolvidos na teia ideológica do cuidado voluntarista.

A atual exigência de formação adequada à função de educador - segundo grau, modalidade normal ou curso superior - ainda não é suficiente para provocar uma ruptura com tais condicionantes das representações acerca do papel e das funções do educador infantil, mas representa um importante e significativo avanço.

A compreensão do novo perfil do profissional de educação infantil parte da premissa de que a educação é um campo vivo de lutas políticas e sociais subordinadas a princípios éticos, estéticos e políticos (BRASIL, 1999) e que é fruto dos sujeitos que a constroem e vivenciam. São sujeitos que acumulam saberes, que desenvolvem projetos práticos e que constroem, neste movimento, uma cultura profissional historicamente circunscrita. Dessa maneira, pensar a educação infantil na relação que estabelece com a política não pode prescindir de uma abordagem que trate do modo de pensar e de atuar que foram por seus agentes incorporados e que supõe tanto o arcabouço teórico quanto os instrumentos técnicos operativos, os recursos materiais, as condições objetivas de desenvolvimento de sua prática profissional.

Assim, importa pensar que o espaço comum, tanto do trabalho do educador infantil quanto da história da profissão, é a própria história da sociedade na capacidade que ela tem de responder aos inúmeros desafios postos pela questão social nas suas diferentes expressões. No campo da educação infantil, a história nos mostra que as respostas organizadas pelo Estado sempre foram dadas em forma de ações da área assistencial, em geral desenvolvidas por instituições filantrópicas ou entidades comunitárias de modo absolutamente desarticulado às políticas educacionais. Neste contexto, a compreensão do papel desenvolvido pelo profissional de educação infantil na produção de saberes e de práticas sobre o seu fazer profissional deve ser traduzida na compreensão da maneira como o Estado, no Brasil, enfrenta os renovados desafios impostos pelo enfrentamento da pobreza. No campo da educação de crianças pequenas, o predomínio de tais ações é acompanhado de explicações que reduzem as questões referentes às desigualdades sociais a questões individuais e familiares, assimiladas pelos agentes como reflexos de dificuldades inerentes ao meio imediato, que afetam, inclusive, o próprio processo de conhecimento da criança na creche e que depois se reproduz na escolarização futura.

É no conjunto ambíguo e contraditório das forças sociais, que tecem e envolvem a percepção do educador infantil do seu trabalho como uma atividade marcada pelo profissionalismo e regulada pelas leis do mercado, que um novo elemento pode representar um retrocesso no campo da politização destas relações de trabalho. Este elemento em nada surpreende o educador infantil, dada a sua proximidade com a história da própria profissão, e ele nos é dado pela crescente desregulamentação das relações de trabalho como resposta ao aumento de uma população de trabalhadores sobrantes às necessidades da acumulação capitalista. Esta desregulamentação surge com um novo apelo ao voluntarismo, aos projetos sociais de responsabilidade social, crivados na perspectiva de refilantropização da questão social que expõe os trabalhadores a armadilhas ideológicas de pensar o campo social como um campo aberto a ações de solidariedade, enaltecedoras de ações de cunho humanista que podem ser desenvolvidas pelos que têm boa vontade, e não, necessariamente, por profissionais.

Neste sentido, a questão da profissionalização do educador infantil ocorre num ambiente em que a área social está contaminada por projetos societários conservadores, articulados à perspectiva neoliberal de satanização do Estado e de beatificação da sociedade civil, que dão o formato ideal para a desregulamentação das relações trabalhistas. O enfrentamento desse dilema certamente depende do grau de mobilização e de politização dos profissionais de educação em geral, e da educação infantil em particular. 
A educação infantil como um acontecimento político: reflexões finais

Tendo como pano de fundo o entendimento da educação infantil como um produto histórico e do educador infantil como um sujeito que tem a sua produção de saberes e de práticas mediada e condicionada pela maneira como o Estado enfrenta, no plano ídeo-político, os desafios postos pelas desigualdades, podemos agora refletir sobre a educação infantil como um acontecimento político. Entendemos que a educação infantil é um campo múltiplo de ideias que têm suas raízes nas práticas cotidianas e em lugares sociais diferenciados e relacionados a estruturas e concepções de poder. Chaú (1990) nos diz que a ideologia é um corpo sistemático de representações e de normas que nos "ensinam" a conhecer e a agir. É dentro desta concepção que construímos o entendimento de que o ato de educar é um acontecimento político do qual sempre nos falou Paulo Freire em suas inúmeras obras. Assim, entendemos que o educador, ao atuar com a criança, o faz de um lugar mais ou menos crítico, renovador ou conservador.

Lugar que não é produto de uma subjetividade construída à parte das relações sociais, nem à projeção de um ideal romântico de sociedade. Lugar, portanto, habitado por contradições e ambiguidades que envolvem a organização, transmissão e produção de conhecimentos que se manifestam em diferentes tipos de linguagem verbal e não verbal, nos cuidados físicos (saúde, higiene e alimentação), nos jogos e brincadeiras. $\mathrm{O}$ desenvolvimento de tais atividades envolve sentimentos, visões de mundo, respeito às diferenças, capacidade de ouvir etc. Lugar que deve combinar, de forma absolutamente indissociável, ética, política e conhecimento, pois sua regulação não depende, na maioria das vezes, de uma esfera pública; trata-se, portanto, de uma ética que se realiza no privado, no espaço muitas vezes restrito do educador com a criança pequena e que tanto pode revelar a grandeza do respeito ao outro e de uma verdadeira concepção de educação como práxis política, como o oposto. No Brasil, a educação infantil transita entre práticas sociais conservadoras, de benemerência e tutela, e práticas comprometidas com a emancipação humana e a construção de uma sociedade mais justa e igualitária.

É nesse contexto que reconhecemos a dinâmica do trabalho da educação infantil: um espaço onde se constroem e se manejam relações de poder, expres- sas na produção de saberes e de práticas sobre o "outro", a criança, que possam considerá-lo como um sujeito social portador de uma singularidade história, ou apagado desta condição e reduzido a mero objeto.

Verificamos que o manejo dessas relações de poder produz-se no dia a dia, mas refletem lutas, valores sociais e éticos mais ou menos organizados e vivenciados na sociedade. Em tempos presentes, é necessário considerar que essas relações são organizadas em uma sociedade que vive, há muito, uma crise de valores manifestos em comportamentos individuais e coletivos, transgressores de normas sociais não condizentes com a vida em sociedade ${ }^{7}$.

Quando olhamos para a realidade da educação infantil em nosso país, deparamo-nos com algumas expressões destas transgressões no permanente status de precariedade que serve de base para o trabalho. A esta transgressão de base juntam-se outras, reveladoras de uma degradada e inadequada forma de fazer política, assentada na discriminação da pobreza, na violência, na refilantropização da questão social.

$\mathrm{Na}$ esfera da vida escolar, as experiências de transgressões advêm da crescente falta de professores $^{8}$, da precariedade dos instrumentos de trabalho dos educadores - recursos audiovisuais, brinquedos, jogos pedagógicos, espaço físico que reduzem suas atividades e que se refletem em rígidas normas de convivência cotidiana.

Crianças em espera, rígidos horários para alimentação, higiene e sono, excessivo controle dos movimentos, pouca liberdade de circulação, práticas de castigo. Tudo isso marca o cenário de uma forma precária de fazer política que manifesta e naturaliza transgressões de normas mínimas de civilidade que revelam contraditórias relações de poder.

Assim, o lugar que o equipamento creche ocupa na estrutura da administração educacional municipal certamente organiza uma dada maneira de se conceber tanto o trabalho do educador infantil quanto o olhar destinado ao usuário do serviço - a criança e sua família. A cultura política local influencia na produção de práticas e de saberes sobre o ato pedagógico como um acontecimento crítico e politizador das diferenças ou como um acontecimento autoritário e reiterativo das desigualdades sociais.

É, pois, a partir de um lugar socialmente determinado, que o encontro com a criança ocorre. $\mathrm{O}$ instrumental técnico operativo do educador e sua formação ídeo-política se entrecruzam num horizonte soci- 
al que apresenta uma finalidade para a qual se dirige a ação educativa. É neste contexto que se coloca o lugar ocupado pelas relações sociais estabelecidas com a criança e sua família; lugar que pode ser de desenvolvimento de um sentido de pertencimento social ou de exclusão; lugar afirmativo de diferenças e singularidades ou de consolidação de subjetividades marcadas pelo apagamento destas singularidades e de transformação de diferenças em marcas indeléveis de desigualdades.

O processo cotidiano de trabalho do educador infantil reflete possibilidades e limites para o manejo destas relações. Dadas as condições de ampliação de demanda por educação infantil num cenário de redução crescente de investimentos públicos na área social, o acesso a uma vaga acaba sendo extremamente seletivo, o que não significa que seja democraticamente instituído. A redução de recursos financeiros refletese, também, na redução do número de pessoal e de indistintas formas de contrato de trabalho?.

Assim, é a partir de um lugar historicamente contextualizado que o trabalho do educador infantil se concretiza e, nesse processo, antecipa possibilidades criadoras de novas formas de viver a experiência de estar no mundo. Os métodos, os projetos, os instrumentos e técnicas de trabalho devem estar pautados no horizonte da humanidade comum e da igualdade. A assimilação destas noções no trabalho cotidiano do educador é todo o tempo historicizado e determinado por relações que extrapolam os muros da escola e que revelam diferentes caminhos e diferentes projetos. É na escolha política e ideológica destes caminhos que podemos tornar o ato pedagógico na educação em geral e na infantil, em particular, um acontecimento político, tecido nos lugares e nas vozes sociais que dão vida às contradições, às ambiguidades e às imprevisibilidades.

\section{Referências}

AMORIM, M. Atirei o pau no gato. São Paulo: Brasiliense, 1992.

O pesquisador e seu outro: Bakhtin nas Ciências Sociais. São Paulo: Musa, 2001.

BRASIL. Conselho Nacional de Educação. Resolução n. 01. Resolução da Câmara de Educação Básica, aprovada em 07 de abril de 1999. Institui as Diretrizes Nacionais para a Educação Infantil. Diário Oficial da união, Brasília, 13 de abril de 1999. Seção 1, p. 18

CHAUÍ, M. Cultura e democracia. São Paulo: Cortez, 1990.

GUATTARI, F.; ROLNIK, S. Micropoliticas - Cartografias do desejo. Rio de Janeiro: Vozes, 2005.
PINTO, M. V. Valor pedagógico do Serviço Social na educação do pequeno escolar. Trabalho de Conclusão de Curso (Graduação em Serviço Social) - Instituto Social de Fortaleza, 1958. Acervo do Centro Brasileiro de Intercâmbio em Serviço Social CBCISS - Rio de Janeiro.

RABELLO, L. (Org.). Infância e adolescência na cultura do consumo. Rio de Janeiro: NAU, 1998.

SILVA, H. M. O Serviço Social em uma creche préprimária. Trabalho de Conclusão de Curso, (Graduação em Serviço Social)-Universidade Federal Fluminense, 1949. Acervo do Centro Brasileiro de Intercâmbio em Serviço Social CBCISS - Rio de Janeiro.

TELLES, G. Revista Serviço Social, São Paulo: 1938. Acervo do Centro Brasileiro de Intercâmbio em Serviço Social CBCISS - Rio de Janeiro.

TODOROV, T. A vida em comum: ensaio de antropologia geral. Campinas: Papirus, 1996.

\section{Notas}

1 Este trabalho foi produzido a partir de análises acumuladas ao longo do desenvolvimento de projetos de pesquisa e extensão na área da Educação Infantil, com apoio daFAPERJ (Bolsas de Iniciação Científica) e do CNPq (Edital Universal/ 2008), todos vinculados ao Departamento de Serviço Social de Niterói da Universidade Federal Fluminense.

2 Sobre as práticas educativas no campo da reiteração das diferenças sociais e sobre a presença da temática da alteridade no campo da pesquisa em ciências humanas, sugiro duas importantes contribuições de Amorim (1992, 2001).

3 Termo retirado de alguns textos desenvolvidos por assistentes sociais escritos nos anos 1930.

4 É nos anos 1990, a partir da LDB de 1996, que a educação infantil se torna a primeira etapa da educação básica, e é reconhecida como um campo de política educacional.

5 O discurso produzido por muitos assistentes sociais que atuaram no campo nesta fase revela a preocupação de tornar a creche um espaço de controle social e moral sobre as famílias das crianças. Sobre isso, ver, entre outros, Pinto (1958), Silva (1949)e Telles(1938).

6 Cabe destacar que a integração dar-se-á no sistema estadual naqueles municípios que ainda não tiverem constituído os seus sistemas próprios de ensino.

7 Todorov (1996)nos fala em seu livro Avida em comum... que, ao se tomar conhecimento das grandes correntes do pensamento europeu sobre o que é humano, chega-se à 
conclusão de que a dimensão social, a vida em comum, geralmente não é concebida como necessária ao homem.

8 Uma queixa muito comum nas famílias de crianças pequenas que estudam na rede pública é o fato de muitos professores faltarem e não terem substitutos, desse modo essas faltas são assumida inteiramente pelas famílias, que precisam abrigar seus filhos durante o horário de aulas.

9 Esta multiplicidade de vínculos dissolve a capacidade organizativa dos trabalhadores e se reflete no processo de trabalho com profissionais sujeitos a um estresse funcional derivado do grande número de horas despendidas com crianças, muitas vezes em precárias condições.

\section{Deise Gonçalves Nunes}

Doutora em Educação pela Universidade Federal do Rio de Janeiro (UFRJ)

Professora assistente do Departamento de Serviço Social da Universidade Federal Fluminense (UFF)

\section{UFF}

Campus do Gragoatá - Bloco "E”

Gragoatá

Niterói - Rio de Janeiro

CEP: 24210-350 